\title{
Natural prey of the jumping spider Menemerus taeniatus (Araneae: Salticidae)
}

\author{
ELCHIN F. HUSEYNOV
}

\begin{abstract}
Institute of Zoology, Azerbaijan Academy of Sciences, Block 504, Passage 1128, Baku 370073, Azerbaijan;
\end{abstract} e-mail: apsheron@list.ru

Keywords. Araneae, Salticidae, jumping spiders, Menemerus taeniatus, diet, prey length

\begin{abstract}
The natural prey of the jumping spider Menemerus taeniatus (L. Koch, 1867) was studied on the Absheron Peninsula, Azerbaijan. The percentage of specimens of $M$. taeniatus found feeding was low (10.7\%). This investigation showed that $M$. taeniatus is a polyphagous predator feeding on a wide range of arthropods, including representatives of eight arthropod orders. The primary food of M. taeniatus was Diptera and Lepidoptera, which collectively made up about two thirds of total prey. The length of prey killed by $M$. taeniatus ranged between 1.10 and $13.00 \mathrm{~mm}$ (mean $6.14 \mathrm{~mm}$ ), which is between 15.2 and $216.7 \%$ (mean $90.3 \%$ ) of the length of their captors. Most frequently taken prey (50\%) were medium-sized arthropods varying between $50-100 \%$ of the spiders' body length.
\end{abstract}

\section{INTRODUCTION}

With over 5000 species, Salticidae is the largest family of spiders (Platnick, 2004). While some aspects of salticid biology, such as silk utilization, sexual and predatory behaviour, are relatively well studied (Richman \& Jackson, 1992; Jackson \& Pollard, 1996), little is known about their prey. A survey of spider literature revealed that more or less detailed quantitative data are only available for a dozen species (Jackson, 1977, 1988a, b; Richman \& Whitcomb, 1981; Jackson \& Blest, 1982; Dean et al., 1987; Horner et al., 1988; Young, 1989; Nyffeler et al., 1990; Żabka \& Kovac, 1996; Bartos, 2002; Wesołowska \& Jackson, 2003). Most of these spiders occur in the tropics or Nearctic, and the only Palaearctic species is that recently studied by Bartos (2002).

The present paper, deals with Menemerus taeniatus (L. Koch, 1867), and is part of a project on the prey of Palaearctic jumping spiders (Guseinov, 2004, 2005; Guseinov et al., 2004). M. taeniatus is a relatively large salticid (adult body length $8-10$ $\mathrm{mm}$ ), with adult males usually slightly smaller than adult females. It is a common Mediterranean species known from the Canary Islands and Morocco, throughout the Pyrenean Peninsula, from the Balkans to Azerbaijan, and in eastern Iran and the south-east of Israel (Wesołowska, 1999; Proszynski, 2004). In Azerbaijan M. taeniatus occurs at low elevations, including semidesert, lowland steppe and submontane forest-steppe zone (Logunov \& Guseinov, 2002), where it is found on cliffs, fences and outside walls of buildings (Guseinov, 2003).

\section{MATERIAL AND METHODS}

This investigation was carried out on the Absheron Peninsula, Azerbaijan. The study site was located near the village Gala. This is an open area of ephemeral semidesert covered with the dwarf shrubs, Artemisia fragrans Willd., and Alhagi pseudoalhagi (M.B.), and short grasses and herbaceous plants, predominantly Calendula persica C.A.M., Senecio vernalis Willd. \& Kar., Medicago denticulata Willd., Erodium cicutarium (L.), Pterotheca marschalliana (Rchb.), Poa bulbosa L., Anisanthea rubens (L.) and Aegilops biuncialis Vis. A row of wooden electricity poles crossed the study area and M. taeniatus was found only on these poles.

Two surveys were conducted in 1998 (30 October and 6 November) and twelve in 1999 (from 13 April to 5 November), which took a total of $23.5 \mathrm{~h}$. All surveys were carried out in daylight, between 11:00 and 17:00. During the surveys, poles were thoroughly searched for M. taeniatus, and the mouthparts of each individual found were inspected with a hand-lens $(\times 4$ magnification) to avoid overlooking small prey. Spiders with prey in their chelicerae were captured with a transparent cup, placed in separate vials containing $75 \%$ ethyl alcohol, and brought back to the laboratory where the prey was identified and the body lengths of both spider and prey measured. Spiders without prey were left in the field. At the same time, all spiders were classified as either: (1) adult males, which could be easily distinguished by their bicoloured (black and grey) palps (all other individuals of M. taeniatus have grey palps); (2) small juveniles, i.e., spiders less than $5 \mathrm{~mm}$ in length; or (3) large juveniles and females, specimens larger than $5 \mathrm{~mm}$, with grey chelicerae. At each survey the numbers of spiders with and without prey were recorded separately for each of these categories.

\section{RESULTS}

In total, 579 specimens of M. taeniatus were observed, 62 of which $(10.7 \%)$ had prey in their chelicerae. This total was made up of 104 males [11 with prey (10.6\%)], 154 small immatures [10 with prey $(6.5 \%)$ ] and 321 large immatures and females [41 with prey $(12.8 \%)]$. There was no statistically significant difference in the percentages of specimens feeding in the different sex-age groups of $M$. taeniatus $\left(\chi^{2}=3.533 ; \mathrm{df}=2 ; \mathrm{P}>0.1\right)$.

Six M. taeniatus individuals dropped their prey before they could be captured. However, for four of them the lost prey items were clearly recognized as three moths and an ant. Thus, the dietary analysis is based on 60 prey items identified to at least the level of order. The prey belonged to eight orders of arthropods; seven from the class Insecta and one from the class Arachnida (Table 1). The dominant prey orders were Lepidoptera and Diptera, which collectively constituted about two thirds of the total prey $(63.3 \%)$. All the Lepidopteran captured were adult moths. The most frequently caught were Psychidae (9 individuals), followed by Thyrididae (4), Gelechidae (3) and Eriocraniidae (1). It is likely that the lost moths also belonged to one of these groups. All Diptera were Brachyceran, represented by Tachinidae (11), Dolichopodidae (2), Therevidae (2), Syrphidae (1), Scathophagidae (1) and Otitidae (1). Spiders (Araneae) were the other order of prey and they accounted for over $10 \%$ of 
TABle 1. Prey of Menemerus taeniatus classified by order, number caught and percentage composition.

\begin{tabular}{lrr}
\hline Prey orders & $\mathrm{N}$ & \multicolumn{1}{c}{$\%$} \\
\hline Lepidoptera & 20 & 33.3 \\
Diptera & 18 & 30.0 \\
Hymenoptera & 4 & 6.7 \\
Coleoptera & 3 & 5.0 \\
"Homoptera" & 3 & 5.0 \\
Heteroptera & 2 & 3.3 \\
Psocoptera & 2 & 3.3 \\
Araneae & 8 & 13.3 \\
Total & 60 & 100.0 \\
\hline
\end{tabular}

total prey. The majority of spiders captured were other Salticidae (6 individuals, including Heliophanus dunini Rakov \& Logunov, 1997, Pellenes epularis (O.P. Cambridge, 1872), Salticus tricinctus (C.L. Koch, 1846), Chalcoscirtus infimus (Simon, 1868), a conspecific and unidentified species). Two other spiders captured were a juvenile Thomisus onustus (Walckenaer, 1802) (Thomisidae) and an unidentified wolf spider (Lycosidae). The remaining prey included four winged ants, Messor denticulatus Lepeletier, three beetles (Bruchidae, Curculionidae, Atellabidae), two bugs (Miridae and unidentified), two winged psocopterans (Psocidae and unidentified), two leafhoppers (Cicadellidae) and one unidentified winged aphid.

Fifty-six prey items were measured. Their length varied from 1.10-13.00 mm (mean \pm SD: $6.14 \pm 2.86 \mathrm{~mm}$ ), which was between 15.2 and $216.7 \%(90.3 \pm 40.7 \%)$ of the length of their captors, which ranged from $2.50-9.50 \mathrm{~mm}(6.87 \pm 1.45 \mathrm{~mm})$. The size distribution of the prey in relation to that of their captors is shown in Fig. 1. The most common were medium-sized arthropods (ranging in body length from 50 to $100 \%$ of that of the spider), and accounted for a half of the total prey measured $(50.0 \%)$. Approximately one third of the prey of M. taeniatus $(33.9 \%)$ consisted of large prey, which exceeded the length of the spider. Most of these did not exceed $150 \%$ of their captor's length and only three were larger. Small prey, less than half the length of the spider, were present in smaller proportions $(16.1 \%)$.

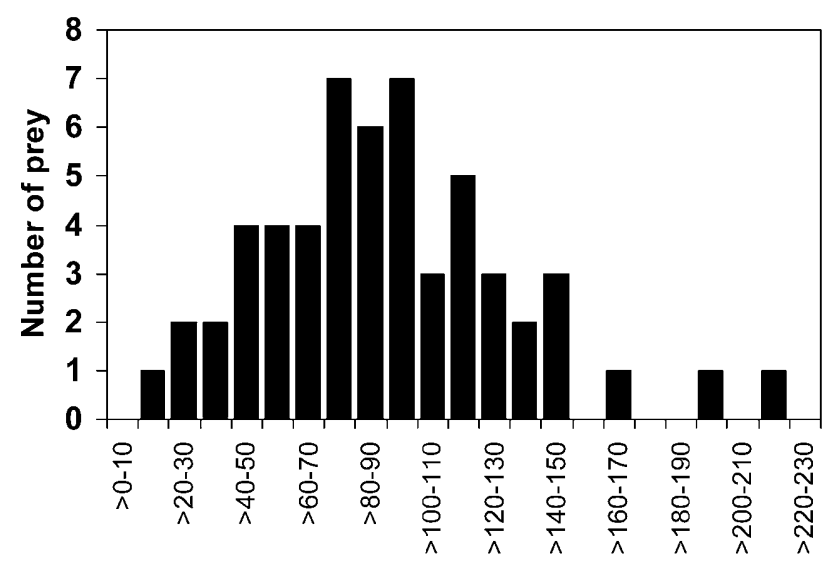

Size categories (\%)

Fig. 1. Number of prey in the different size categories (body lengths of prey expressed as percentages of the body length of their captors).

\section{DUSCUSSION}

The percentage of M. taeniatus individuals found feeding was low $(10.7 \%)$, which is typical of cursorial spiders (Nentwig, 1986; Nyffeler \& Breene, 1990). It should be noted, however, that this value is high compared to that recorded for other jumping spiders (Jackson, 1977; Dean et al., 1987; Young, 1989). Another interesting fact is that males of M. taeniatus captured prey almost as frequently as females and immatures. This contrasts with the observations on other salticids (Jackson, 1977; Givens, 1978; Sathiamma et al., 1987), including congeneric Menemerus semilimbatus (Hahn, 1827) (Guseinov, 2004), in which males fed significantly less frequently than females. The reason for this difference is unclear.

This investigation indicates that $M$. taeniatus is a polyphagous predator feeding on a wide range of arthropods. Polyphagy is characteristic of jumping spiders (Nyffeler, 1999), with the exception of Portia fimbriata (Doleschall, 1859), which was observed to feed almost exclusively on spiders (Jackson \& Blest, 1982; Clark \& Jackson, 2000). The predominance of moths and flies in the diet of M. taeniatus is probably due to these insects frequently settling on wooden poles. Similarly, these two groups of insects accounted for about $70 \%$ of the prey of M. semilimbatus foraging on stone walls (Guseinov, 2004). However, in the diet of the latter species flies were significantly more abundant than moths. It is remarkable, that $86.7 \%$ of the prey of M. taeniatus consisted of winged insects, which is characteristic of jumping spiders that live above ground level, while epigeic salticids feed primarily on arthropods that crawl (Guseinov, 1999). Unlike some species of salticids, which specialise in catching dangerous prey such as worker ants or web-building spiders (Li \& Jackson, 1996), M. taeniatus captured almost exclusively soft-bodied, "harmless" arthropods. All the ants caught by this species were either males or queens of Messor denticulatus. Unlike workers, reproductive individuals of ants are virtually defenceless and are easily caught by jumping spiders (Edwards et al., 1974).

The study of prey size preference in spiders has shown that most cursorial spiders, including salticids, do not catch prey that exceeds $150 \%$ of their own body length. The preferred prey length tends to be equal to or less than the length of the spider (Nentwig \& Wissel, 1986). The findings reported here agree with this generalization. Most of the prey of M. taeniatus (ca. $70 \%$ ) were smaller than the spider, while those that were larger than their captors usually did not exceed $150 \%$ of the spider's length.

ACKNOWLEDGEMENTS. I wish to thank E. Shaw (Manchester, UK) and anonymous reviewer for their kind linguistic help.

\section{REFERENCES}

BARTOS M. 2002: The prey of Yllenus arenarius (Araneae, Salticidae). In Samu F. (ed.): Abstracts of 20th European Colloquium of Arachnology. Balogh es Tarza Nyomda, Szombathely, Hungary, p. 25.

CLARK R.J. \& JACKSON R.R. 2000: Web use during predatory encounters between Portia fimbriata, an araneophagic jumping spider, and its preferred prey, other jumping spiders. N.Z. J. Zool. 27: 129-136.

Dean D.A., Sterling W.L., Nyffeler M. \& Breene R.G. 1987: Foraging by selected spider predators on the cotton fleahopper and other prey. Southwest. Entomol. 12: 263-270.

Edwards G.B., Caroll J.F. \& Whitcomb W.H. 1974: Stoidis aurata (Araneae: Salticidae), a spider predator of ants. Fla Entomol. 57: 337-346. 
Givens R.P. 1978: Dimorphic foraging strategies of a salticid spider (Phidippus audax). Ecology 59: 309-321.

Guseinov E.F. 1999: Spiders of Lenkoran Nature Area and Absheron Peninsula, Azerbaijan. Ph.D. thesis, Institute of Zoology, Azerbajdjan Acad. Sci., Baku, 29 pp. [in Russian, English abstr.].

GUSEINOV E.F. 2003: Microhabitat preferences of the jumping spiders (Araneae: Salticidae) inhabiting the Absheron Peninsula, Azerbaijan. In Kipyatkov V.E. \& Logunov D.V. (eds): Abstracts of 21st European Colloquium of Arachnology. St. Petersburg University Press, St. Petersburg, p. 37.

GusEINOV E.F. 2004: Natural prey of the jumping spider Menemerus semilimbatus (Hahn, 1827) (Araneae: Salticidae), with notes on its unusual predatory behaviour. In Logunov D.V. \& Penney D. (eds): European Arachnology 2003. Proceedings of the 21st European Colloquium of Arachnology, St. Petersburg, 4-9 August 2003. St. Petersburg University Press, St. Petersburg, pp. 93-100.

Guseinov E.F. 2005: Natural prey of the jumping spider Salticus tricinctus (Araneae, Salticidae). Bull. Br. Arachnol. Soc. 13: 130-132.

Guseinov E.F., Cerveira A.M. \& JaCKSON R.R. 2004: The predatory strategy, natural diet and life cycle of Cyrba algerina, an araneophagic jumping spider (Salticidae: Spartaeinae) from Azerbaijan. N.Z. J. Zool. 31: 291-303.

Horner N.V., Stangl F.B. \& Fuller G.K. 1988: Natural history observations of Salticus austinensis (Araneae, Salticidae) in North-Central Texas. J. Arachnol. 16: 260-262.

JACKSON R.R. 1977: Prey of the jumping spider Phidippus johnsoni (Araneae: Salticidae). J. Arachnol. 5: 145-149.

JACKSON R.R. 1988a: The biology of Jacksonoides queenslandica, a jumping spider (Araneae: Salticidae) from Queensland: intraspecific interactions, web-invasion, predators, and prey. N.Z. J. Zool. 15: 1-37.

JACKSON R.R. 1988b: The biology of Tauala lepidus, a jumping spider (Araneae: Salticidae) from Queensland: display and predatory behaviour. N.Z. J. Zool. 15: 347-364.

JACKSON R.R. \& BLEST A.D. 1982: The biology of Portia fimbriata, a web-building jumping spider (Araneae, Salticidae) from Queensland: utilization of webs and predatory versatility. $J$. Zool. (Lond.) 196: 255-293.

JACKSON R.R. \& POLLARD S.D. 1996: Predatory behaviour of jumping spiders. Annu. Rev. Entomol. 41: 287-308.

LI D. \& JACKSON R.R. 1996: Prey-specific capture behaviour and prey preferences of myrmicophagic and araneophagic jumping spiders (Araneae: Salticidae). Proc. 13th Int. Congr. Arachnol., Geneva, 3-8 Sept. 1995. Rev. Suisse Zool., Vol. hors serie, pp. 423-436.
Logunov D.V. \& Guseinov E.F. 2002: Faunistic review of the jumping spiders of Azerbaijan (Aranei: Salticidae), with additional faunistic records from neighbouring Caucasian countries. Arthrop. Selecta 10[2001]: 243-260.

NeNTWIG W. 1986: Non-webbuilding spiders: prey specialists or generalists? Oecologia 69: 571-576.

Nentwig W. \& Wissel C. 1986: A comparison of prey lengths among spiders. Oecologia 68: 595-600.

NyffeleR M. 1999: Prey selection of spiders in the field. $J$. Arachnol. 27: 317-324.

Nyffeler M. \& Breene R.G. 1990: Evidence of low daily food consumption by wolf spiders in meadowland and comparison with other cursorial hunters. J. Appl. Entomol. 110: 73-81.

Nyffeler M., Breene R.G. \& DeAn D.A. 1990: Facultative monophagy in the jumping spider, Plexippus paykulli (Audouin) (Araneae: Salticidae). Peckhamia 2: 92-96.

Platnick N.I. 2004: The World Spider Catalog, Version 5.0 $A M N H$. [http://research.amnh.org/entomology/spiders/catalog 81-87/INTRO3.html].

Proszynski J. 2004: Salticidae (Araneae) of the World. Part I. Diagnostic Drawings Library. Part II. Catalogue of Salticidae (Araneae) synthesis of quotations in the world literature since 1940, with basic taxonomic data since 1758. Version March, 2004. [http://salticidae.org/salticid/main.htm].

Richman D.B. \& JACKSON R.R. 1992: A review of the ethology of jumping spiders (Araneae, Salticidae). Bull. Br. Arachnol. Soc. 9: 33-37.

Richman D.B. \& Whitcomb W.H. 1981: The ontogeny of Lyssomanes viridis (Walckenaer) (Araneae: Salticidae) on Magnolia grandiflora L. Psyche 88: 127-133.

Sathiamma B., Jayapal S.P. \& Pillai G.P. 1987: Observations on spiders (Order: Araneae) predacious on the coconut leaf eating caterpillar Opisina arenosella Wlk. (Nephantis serinopa Meyrick) in Kerala: feeding potential. Entomon 12: 45-47.

WesoŁowsKa W. 1999: A revision of the spider genus Menemerus in Africa (Araneae: Salticidae). Genus 10: 251-353.

WeSOŁOWSKA W. \& JACKSON R.R. 2003: Evarcha culicivora sp. nov., a mosquito-eating jumping spider from East Africa (Araneae: Salticidae). Ann. Zool. 53: 335-338.

Young O.P. 1989: Field observations of predation by Phidippus audax (Araneae: Salticidae) on arthropods associated with cotton. J. Entomol. Sci. 24: 266-273.

ŻABKA M. \& KovaC D. 1996: Paracyrba wanlessi - a new genus and species of Spartaeinae from Peninsular Malaysia with notes on its biology (Arachnida: Araneae: Salticidae). Senckenb. Biol. 76: 153-161.

Received September 27, 2004; revised and accepted April 4, 2005 